\title{
Can the cervical length in mid-trimester predict the use of vacuum in vaginal delivery?
}

\author{
Jee Yoon Park, MD¹, Sun Min Kim, MD², Jeenah Sohn, MD², Sejin Kim, MD¹, Eunjin Song, MD', \\ Byoung Jae Kim, MD², Hye Won Jeon, MD²
}

Department of Obstetrics and Gynecology, ${ }^{1}$ Seoul National University Bundang Hospital, Seongnam, ${ }^{2}$ Seoul Metropolitan Government-Seoul National University Boramae Medical Center, Seoul, Korea

\section{Objective}

This study aimed to evaluate whether an increased cervical length $(C L)$ measured in the mid-trimester is associated with vacuum-assisted vaginal delivery.

\section{Methods}

This retrospective cohort study included women who delivered vaginally in Seoul National University Bundang Hospital $(n=820)$ and Boramae Medical Center $(n=509)$ between January 2017 and February 2019. Multifetal pregnancies and preterm births before 37 weeks of gestation were excluded. Only those cases in which CL was measured at 18-22 weeks of gestation for the purpose of screening for preterm birth risk in each institution were analyzed $(n=537)$. Other significant risk factors were reviewed.

\section{Results}

The median gestational age at delivery was 39.4 weeks (range, 37.0-41.6 weeks); $18.6 \%$ (100/537) were vacuumassisted delivery. There was no relationship between mid-trimester $\mathrm{CL}$ and vacuum-assisted delivery (odds ratio [OR], 0.96; 95\% confidence interval $[\mathrm{Cl}], 0.57-1.62)$, while nulliparity was associated with a higher risk (OR, 3.64; $95 \% \mathrm{Cl}$, 1.55-8.57) than multiparity. When the population was divided into 3 groups by $\mathrm{CL}$ range, vacuum-assisted delivery rates increased as $\mathrm{CL}$ length increased in nulliparous women.

Conclusion

Mid-trimester CL did not predict the need for vacuum-assisted vaginal delivery.

Keywords: Vacuum extraction; Operative birth; Delivery; Cesarean section

\section{Introduction}

Operative vaginal delivery is a labor management option that can avoid cesarean section in some specific situations, usually almost always at the end of the second stage [1-3]. When the scalp of the fetus is visible at the introitus or the leading point of the fetal head is placed over station $+2 \mathrm{~cm}$, operative delivery is performed if the delivery must be expedited due to the acute presentation of non-reassuring fetal heart rate monitoring or maternal exhaustion from prolonged labor [4]. In this advanced stage of labor, cesarean section carries an increased risk of maternal morbidity such as bladder injury or difficulty elevating the fetal head through the uterine incision because the fetus is far more advanced in the pelvic cavity [5]. Preparations for cesarean section includ- ing cooperation with anesthesiologists and other faculties are non-negligible and another reason to consider operative

Received: 2019.05.28. Revised: 2019.08.16. Accepted: 2019.09.24. Corresponding author: Hye Won Jeon, MD

Department of Obstetrics and Gynecology, Seoul Metropolitan Government-Seoul National University Boramae Medical Center, 20 Boramae-ro 5-gil, Dongjak-gu, Seoul 07061, Korea

E-mail: jshmom04@gmail.com

https://orcid.org/0000-0001-9751-2982

Articles published in Obstet Gynecol Sci are open-access, distributed under the terms of the Creative Commons Attribution Non-Commercial License (http://creativecommons. org/licenses/by-nc/3.0/) which permits unrestricted non-commercial use, distribution, and reproduction in any medium, provided the original work is properly cited.

Copyright $\odot 2020$ Korean Society of Obstetrics and Gynecology 


\title{
Obstetrics \& Gynecology Science
}

\author{
Vol. 63, No. 1, 2020
}

vaginal delivery.

Merriam et al. [2] reported that the rate of vacuum-assisted deliveries in the United States decreased slightly from about $6 \%$ in 2005 to $4 \%$ in 2013. In this population-based study, the factors related to the increased likelihood of operative delivery included diabetic disorders, nulliparity, labor induction, and chorioamnionitis. The well-known complications of operative deliveries are third- and fourth-degree birth canal lacerations and acute perinatal morbidities such as scalp lacerations, cephalohematoma, and subgaleal hemorrhage [4,6-11]. These adverse outcomes after operative delivery often become a troublesome for physicians despite successful vaginal delivery. Moreover, it is difficult to convince the patients and family members about the consequences despite the unclear association between neonatal complications and operative delivery. Thus, it would be helpful if the prediction of operative delivery before the initiation of labor is possible.

Numerous trial of labor studies have examined the success of vaginal delivery and the rate of cesarean sections [12]; however, attempts to predict operative delivery are lacking, and studies are usually limited to the identification of risk factors in a large population or meta-analysis $[5,13,14]$. Several studies reported that an increased mid-trimester cervical length $(C L)$ was associated with a higher risk of cesarean section [15-18]. Nevertheless, there are conflicting results of the association between a longer mid-trimester $\mathrm{CL}$ and the rate of cesarean delivery unlike the relationship between a short $\mathrm{CL}$ and the likelihood of preterm birth [19-21].

The idea to investigate the association between mid-trimester $C L$ and vaginal delivery failure during trial of labor started from the hypothesis that a cervix that does not shorten during the second trimester might be an obstacle or predisposition for an ineffective progression of labor. This study was designed to determine if the use of vacuum-assisted delivery and not only the likelihood of emergency cesarean section after trial of labor is associated with mid-trimester CL. Kahrs et al. [13] studied several sonographic findings to predict the success of vacuum-assisted deliveries; however, the ultrasonographic evaluations were performed only in nulliparous women who were diagnosed with a prolonged second stage of labor.

This study aimed to determine whether mid-trimester $C L$ is associated with the rate of operative delivery.

\section{Materials and methods}

\section{Study design}

This retrospective study included consecutive women who achieved vaginal delivery at Seoul National University Bun-

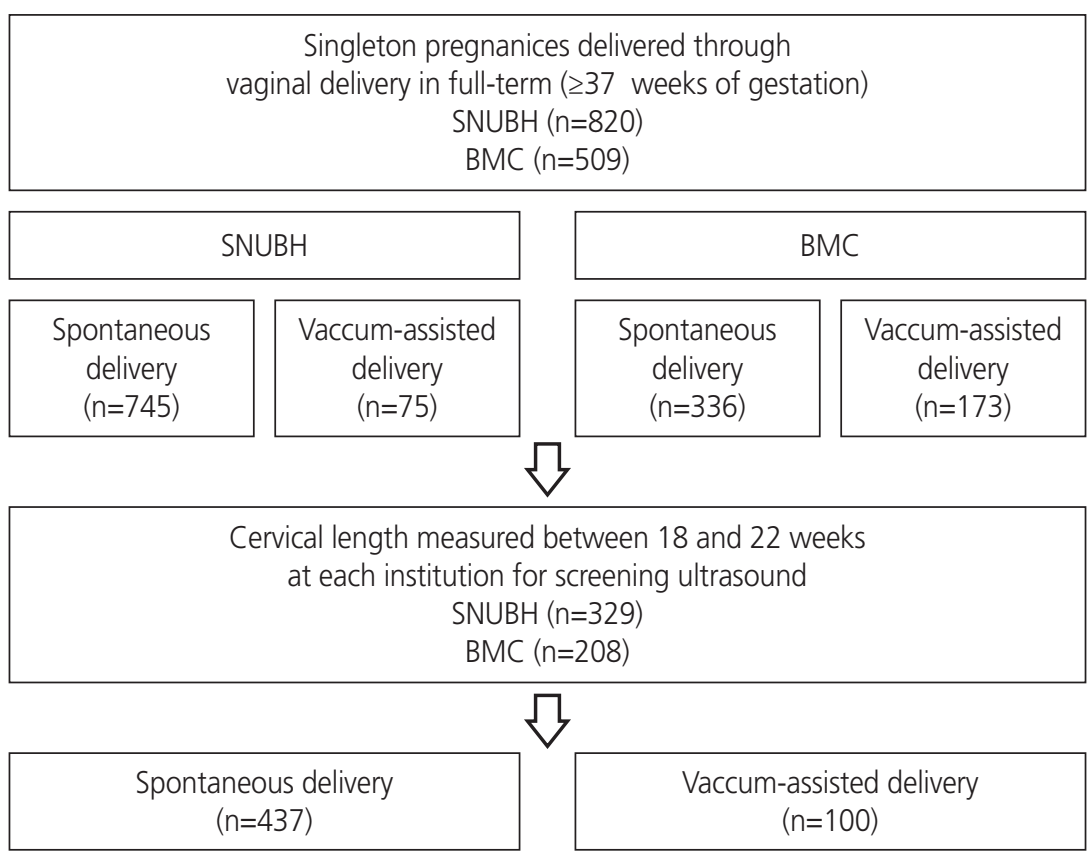

Fig. 1. Flowchart of the study population. SNUBH, Seoul National University Bundang Hospital; BMC, Boramae Medical Center. 


\section{Obstetrics \& Gynecology Science}

Jee Yoon Park, et al. Cervical length in mid-trimester and vacuum-assisted delivery

dang Hospital (SNUBH; $\mathrm{n}=820$ ) or Boramae Medical Center (BMC; n=509) between January 2017 and February 2019. Only singleton pregnancies delivered at or beyond 37 weeks of gestation were included; multifetal pregnancies and cases of fetal death in utero were excluded. Among them, those for whom reliable data on CL measured at 18-22 weeks of gestation for the purpose of screening for the risk of preterm birth in each institution were analyzed $(n=537)$ (Fig. 1). The study group was divided into 3 groups according to every $1 \mathrm{~cm}$ of $\mathrm{CL}$.

\section{Mode of delivery}

Birth attendants at both institutions used vacuum assistance only; forceps were used in no cases. The vacuum cups used in the study population were soft or metal; however, the tool used in each case could not be identified through the medical records. Once the cup was placed atop the fetal scalp by the physician, the device created gradual vacuum pressure until the total negative pressure reached $300 \mathrm{mmHg}$.

\section{Significant variables to determine risk factors}

Obstetric and medical factors with a possible association with operative delivery were identified and analyzed. Infor- mation was collected on maternal characteristics including age, parity, mid-trimester $C L$, gestational age at the time of $\mathrm{CL}$ measurement, hypertensive disorder, diabetic disorder, body weight, and height at delivery. Obstetric conditions such as the use of intravenous oxytocin for labor induction or augmentation of spontaneous labor pain, the application of epidural anesthesia, gestational age at delivery, and neonatal birthweight were reviewed in the medical records.

\section{Statistical analysis}

Data were tested for normality using the KolmogorovSmirnov test. Continuous variables were compared using the Mann-Whitney $U$ test or Kruskal-Wallis analysis. The proportions were compared using Fisher's exact test or the $\chi^{2}$ test. Logistic regression was used to determine the association between mid-trimester $C L$ and vacuum delivery. Multivariate analysis was then performed to adjust for variables confounding the outcomes and identify risk factors. $P$-values $<0.05$ were considered statistically significant, and the analysis was performed using SPSS version 22 (IBM SPSS Inc., Armonk, NY, USA).

Table 1. Clinical characteristics and pregnancy outcomes of the study population according to the mode of delivery

\begin{tabular}{|c|c|c|c|}
\hline Characteristics & $\begin{array}{l}\text { Spontaneous delivery } \\
\qquad(n=437)\end{array}$ & $\begin{array}{l}\text { Vacuum-assisted delivery } \\
\qquad(\mathrm{n}=100)\end{array}$ & $P$-value \\
\hline Age (yr) & $33(31-36)$ & $34(30-37)$ & 0.709 \\
\hline Nulliparity & $49.4(216 / 437)$ & $79.0(79 / 100)$ & $<0.001$ \\
\hline Cervical length in mid-trimester (cm) & $3.8(3.4-4.2)$ & $3.9(3.5-4.2)$ & 0.185 \\
\hline Gestational age at cervical length measuring (wk) & $20.9(20.4-21.3)$ & $21.0(20.6-21.4)$ & 0.196 \\
\hline Hypertensive disorder & $6.4(28 / 437)$ & $4.0(4 / 100)$ & 0.484 \\
\hline Diabetic disorder & $7.3(32 / 437)$ & $6.0(6 / 100)$ & 0.829 \\
\hline Maternal weight at delivery $(\mathrm{kg})$ & $68.0(62.1-74.5)$ & $66.9(62.1-73.8)$ & 0.622 \\
\hline Maternal height at delivery $(\mathrm{cm})$ & $162.5(158.5-166.0)$ & $161.8(158.0-165.0)$ & 0.173 \\
\hline Maternal BMI & $25.7(23.9-28.0)$ & $25.8(23.9-28.0)$ & 0.843 \\
\hline ... Maternal obesity $\left(\mathrm{BMI} \geq 30 \mathrm{~kg} / \mathrm{m}^{2}\right)$ at delivery & $13.7(53 / 388)$ & $8.4(8 / 95)$ & 0.227 \\
\hline Prepregnancy body mass index & $20.7(19.5-22.8)$ & $20.7(18.6-21.8)$ & 0.237 \\
\hline Use of intravenous oxytocin during labor & $34.6(151 / 437)$ & $54.0(54 / 100)$ & $<0.001$ \\
\hline Epidural anesthesia & $76.0(332 / 437)$ & $92.0(92 / 100)$ & $<0.001$ \\
\hline Gestational age at delivery (wk) & $39.3(38.4-40.0)$ & $39.4(38.6-40.1)$ & 0.337 \\
\hline Birthweight (g) & $3,245(2,980-3,465)$ & $3,218(2,978-3,495)$ & 0.608 \\
\hline
\end{tabular}

Values are expressed as the median (interquartile range) for continuous variables and percentage for categorical variables.

BMI, body mass index. 


\title{
Obstetrics \& Gynecology Science
}

\author{
Vol. 63, No. 1, 2020
}

\section{Results}

Fig. 1 shows the study population from each institution. Only term pregnancies were included because vacuum delivery is less often recommended in preterm births due to the high incidence of hemorrhagic complications such as intraventricular hemorrhage. Among the 1,329 singleton pregnancies (820 in SNUBH and 509 in BMC), data for the mid-trimester $\mathrm{CL}$ measured during a routine ultrasound examination were available for 537 pregnancies. Among them, 18.9\% (100/537) of the patients underwent vacuum-assisted vaginal delivery.

Various factors were compared according to the use of vacuum assistance (Table 1). The proportion of nulliparous women was significantly higher in the vacuum-assisted delivery group than in the spontaneous delivery group $(79.0 \%$ vs. $49.4 \%, P<0.001)$. The median $C L$ and gestational age at the time of the measurement were comparable. The proportions of cases in which intravenous oxytocin was used for induction or to augment labor or uterine contractions and the application of epidural anesthesia were both significantly higher in the vacuum-assisted delivery group than in the other group (both $P<0.001$ ). The mean neonatal birthweight did not differ between groups.

Table 2 shows the risk factors and associations with vacuum use analyzed by logistic regression analysis. In the univariate analysis, nulliparity, intravenous oxytocin use, and epidural anesthesia use were associated with vacuumassisted delivery. However, in multivariate analysis, epidural anesthesia was not associated with vacuum use; otherwise, nulliparity and intravenous oxytocin use remained significant risk factors after the adjustment for other factors. Moreover, gestational age at delivery was associated with vacuumassisted delivery in multivariate analysis. Mid-trimester $\mathrm{CL}$ was not associated with vacuum use in the logistic regression analysis.

In only nulliparous women, the rates of vacuum use were compared by every $1 \mathrm{~cm}$ of $\mathrm{CL}$ for easier application in clinical settings $(<3 \mathrm{~cm}, 3.0-3.9 \mathrm{~cm}$, and $\geq 4 \mathrm{~cm})$. In the groups with a $C L$ of $3.0-3.9 \mathrm{~cm}$ and $\geq 4 \mathrm{~cm}$, the rates of vacuumassisted delivery were 25.8\% (41/159) and 30.5\% (36/118), respectively, higher than that of the group with a $C L$ of $<3 \mathrm{~cm}(6.3 \%$ [1/16]) (Fig. 2). The $P$-value on the analysis of a linear by linear association was 0.074 , while the $P$-values of the differences among groups in the post hoc analysis were all below 0.05 . The odds ratio (OR) was 4.5 (95\% confidence

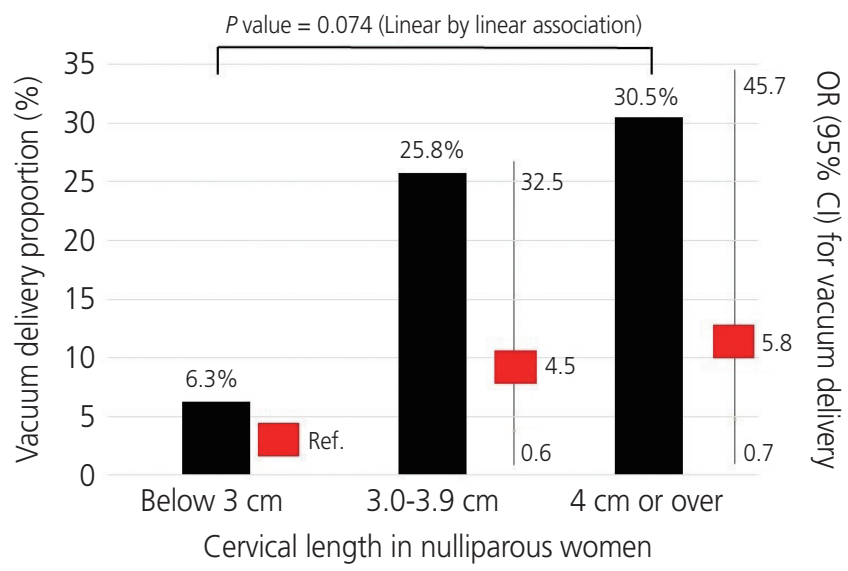

Fig. 2. Proportion and odds ratios (ORs) of vacuum-assisted delivery by mid-trimester cervical length in nulliparous women (adjusted for oxytocin use). $\mathrm{Cl}$, confidence interval; Ref., reference value.

Table 2. Risk factors of vacuum-assisted delivery analyzed by logistic regression analysis

\begin{tabular}{|c|c|c|c|c|}
\hline \multirow{2}{*}{ Risk factors } & \multicolumn{2}{|c|}{ Univariate } & \multicolumn{2}{|c|}{ Multivariate } \\
\hline & OR $(95 \% \mathrm{Cl})$ & $P$-value & OR $(95 \% \mathrm{Cl})$ & $P$-value \\
\hline Maternal age (yr) & $1.00(0.94-1.05)$ & 0.872 & $0.92(0.82-1.02)$ & 0.101 \\
\hline Nulliparity & $3.85(2.30-6.45)$ & $<0.001$ & $3.11(1.26-0.67)$ & 0.014 \\
\hline Cervical length in mid-trimester (cm) & $1.19(0.85-1.67)$ & 0.302 & $0.94(0.53-1.65)$ & 0.825 \\
\hline Maternal obesity $\left(\mathrm{BMI} \geq 30 \mathrm{~kg} / \mathrm{m}^{2}\right)$ at delivery & $0.58(0.27-1.27)$ & 0.581 & $0.52(0.10-2.63)$ & 0.427 \\
\hline Use of intravenous oxytocin & $2.22(1.43-3.45)$ & $<0.001$ & $4.46(2.08-9.55)$ & $<0.001$ \\
\hline Epidural anesthesia & $3.64(1.71-7.74)$ & 0.001 & $1.51(0.41-5.59)$ & 0.537 \\
\hline Gestational age at delivery (wk) & $1.09(0.88-1.35)$ & 0.439 & $1.65(1.09-2.50)$ & 0.018 \\
\hline Birthweight (g) & $1.00(1.00-1.00)$ & 0.291 & $1.00(0.99-1.00)$ & 0.565 \\
\hline
\end{tabular}

$\mathrm{OR}$, odds ratio; $\mathrm{Cl}$, confidence interval; $\mathrm{BMI}$, body mass index. 


\section{Obstetrics \& Gynecology Science}

Jee Yoon Park, et al. Cervical length in mid-trimester and vacuum-assisted delivery

interval $[\mathrm{Cl}], 0.6-35.2 ; P=0.156)$ and $5.8(95 \% \mathrm{Cl}, 0.7-45.7$; $P=0.098)$ using the group with a $\mathrm{CL}$ of $<3 \mathrm{~cm}$ as the reference value for the logistic regression analysis. Both were higher than that of the group with a $\mathrm{CL}<3 \mathrm{~cm}$; however, the difference was not statistically significant.

\section{Discussion}

The principal study findings were as follows: 1) Mid-trimester $\mathrm{CL}$ was not associated with vacuum assistance during delivery; 2) Nulliparity, gestational age at delivery, and intravenous oxytocin use were independent risk factors for vacuum delivery in full-term singleton pregnancies on multivariate regression analysis; 3) When the population was divided into 3 groups by every $1 \mathrm{~cm}$ of $\mathrm{CL}$, the proportion of vacuum deliveries increased as the measurement increased; however, the difference did not reach the statistical significance.

A short mid-trimester $\mathrm{CL}$ is a well-known independent risk factor for preterm birth; therefore, the universal screening of mid-trimester $\mathrm{CL}$ is recommended to identify cases at high risk of preterm delivery [19,21-28]. Similar to the association between cervical shortening and early spontaneous delivery, researchers consequently hypothesized that a longer $\mathrm{CL}$ would be associated with prolonged pregnancy (post-term delivery) or difficult spontaneous delivery [29-31]. A few studies have examined the relationship between $\mathrm{CL}$ at term or immediately before delivery and vaginal delivery success [5,32]. Ramanathan et al. [32] demonstrated that, when the $\mathrm{CL}$ was $\geq 4 \mathrm{~cm}$ at 37 weeks of gestation, $89 \%$ (8/9) of nulliparous women underwent cesarean section after trial of labor due to failure to progress or fetal distress. One meta-analysis demonstrated that $\mathrm{CL}$ before labor induction did not predict the mode of delivery or induction success [12].

Smith et al. [18] demonstrated a relationship between cesarean section rate and the CL measured at 23 weeks of gestation. They divided the subjects into quartiles by midtrimester $\mathrm{CL}$; the reported $\mathrm{OR}$ for cesarean section in the fourth quartile was $1.81(95 \% \mathrm{Cl}, 1.66-1.97)$ compared to the first quartile. Miller et al. [15] reported the increased midtrimester CL was significantly associated with a higher frequency of cesarean section in singleton nulliparous women. In the study, the frequency of cesarean section increased with odds of $20.3 \%$ for every additional centimeter of CL. Van de Mheen et al. [17] performed a similar study on twin pregnancy; however, the mid-trimester $C L$ was not associated with a risk of cesarean section. Unlike that study, Sung et al. [16] reported that a longer $C L$ in mid-pregnancy was a risk factor for cesarean section in twins and higher rates of cesarean deliveries as the quartiles of the study population increased.

Although the related relationships between sonographically measured $C L$ values and trial of labor success are conflicting, many researchers have explored the possibility of applying $\mathrm{CL}$ to other additional obstetric outcomes rather than to predict preterm birth. As a diagnostic tool, measuring $\mathrm{CL}$ is a noninvasive, relatively easy, and widely used technique. Operative deliveries such as those using vacuum assistance avoid cesarean section; however, because of the increased rates for higher-degree lacerations of the birth canal and several neonatal complications such as cephalohematoma and subgaleal hematoma, birth attendants might prefer cesarean section in the clinical setting to reduce the chance of post-procedural risks. From this point of view, an effective tool to predict difficult deliveries or need for vacuum assistance must be identified.

The main strength of this study is that it attempted to discern the association between mid-trimester $\mathrm{CL}$ and vacuumassisted delivery. The study population was drawn from 2 different institutions, and the sample size was adequate because pure were used of relatively low-risk singleton pregnancies. However, it is limited by its retrospective nature. Future prospective studies on the rates of operative deliveries for various conditions of the population are required to identify a model for predicting difficult vaginal deliveries.

In conclusion, mid-trimester $\mathrm{CL}$ is not a useful predictor for future vacuum-assisted delivery in cases of successful term vaginal deliveries.

\section{Conflict of interest}

No potential conflict of interest relevant to this article was reported.

\section{Ethical approval}

The study was approved by the Institutional Review Board of Seoul National University Bundang Hospital (No. B-1905- 


\section{Obstetrics \& Gynecology Science}

Vol. 63, No. 1, 2020

540-111) and Institutional Review Board of Seoul Metropolitan Government-Seoul National University Boramae Medical Center (No. 30-2019-51) and performed in accordance with the principles of the Declaration of Helsinki.

\section{Patient consent}

Written informed consents were obtained.

\section{References}

1. Jeon J, Na S. Vacuum extraction vaginal delivery: current trend and safety. Obstet Gynecol Sci 2017;60:499-505.

2. Merriam AA, Ananth CV, Wright JD, Siddiq Z, D'Alton ME, Friedman AM. Trends in operative vaginal delivery, 2005-2013: a population-based study. BJOG 2017;124:1365-72.

3. Verhoeven CJ, Nuij C, Janssen-Rolf CR, Schuit E, Bais JM, Oei SG, et al. Predictors for failure of vacuum-assisted vaginal delivery: a case-control study. Eur J Obstet Gynecol Reprod Biol 2016;200:29-34.

4. McQuivey RW. Vacuum-assisted delivery: a review. J Matern Fetal Neonatal Med 2004;16:171-80.

5. Metz TD, Gonzalez C, Allshouse AA, Henry E, Esplin S. Influence of patient-level factors on mode of delivery among operative vaginal delivery candidates in modern practice. Am J Perinatol 2017;34:974-81.

6. Muraca GM, Sabr Y, Lisonkova S, Skoll A, Brant R, Cundiff GW, et al. Morbidity and mortality associated with forceps and vacuum delivery at outlet, low, and midpelvic station. J Obstet Gynaecol Can 2019;41:327-37.

7. Ghidini A, Stewart D, Pezzullo JC, Locatelli A. Neonatal complications in vacuum-assisted vaginal delivery: are they associated with number of pulls, cup detachments, and duration of vacuum application? Arch Gynecol Obstet 2017;295:67-73.

8. Lund NS, Persson LK, Jangö H, Gommesen D, Westergaard HB. Episiotomy in vacuum-assisted delivery affects the risk of obstetric anal sphincter injury: a systematic review and meta-analysis. Eur J Obstet Gynecol Reprod Biol 2016;207:193-9.

9. Dall'Asta A, Ghi T, Pedrazzi G, Frusca T. Does vacuum delivery carry a higher risk of shoulder dystocia? Review and meta-analysis of the literature. Eur J Obstet Gynecol Reprod Biol 2016;204:62-8.

10. Lacker C. Preventing maternal and neonatal harm during vacuum-assisted vaginal delivery. Am J Nurs 2012;112:65-9.

11. Vacca A. Vacuum-assisted delivery. Best Pract Res Clin Obstet Gynaecol 2002;16:17-30.

12. Hatfield AS, Sanchez-Ramos L, Kaunitz AM. Sonographic cervical assessment to predict the success of labor induction: a systematic review with metaanalysis. Am J Obstet Gynecol 2007;197:186-92.

13. Kahrs BH, Usman S, Ghi T, Youssef A, Torkildsen EA, Lindtjorn $E$, et al. Sonographic prediction of outcome of vacuum deliveries: a multicenter, prospective cohort study. Am J Obstet Gynecol 2017;217:69.e1-10.

14. Herstad L, Klungsøyr K, Skjaerven R, Tanbo T, Forsén $L$, Åbyholm T, et al. Maternal age and emergency operative deliveries at term: a population-based registry study among low-risk primiparous women. BJOG 2015;122:1642-51.

15. Miller ES, Sakowicz A, Grobman WA. Association between second-trimester cervical length and primary cesarean delivery. Obstet Gynecol 2013;122:863-7.

16. Sung SJ, Lee SM, Oh S, Choi JH, Park JY, Kim BJ, et al. Mid-pregnancy cervical length as a risk factor for cesarean section in women with twin pregnancies. J Perinat Med 2018;46:780-5.

17. van de Mheen L, Schuit E, Liem SM, Lim AC, Bekedam DJ, Goossens SM, et al. Second-trimester cervical length as risk indicator for Cesarean delivery in women with twin pregnancy. Ultrasound Obstet Gynecol 2015;46:579-84.

18. Smith GC, Celik E, To M, Khouri O, Nicolaides KH; Fetal Medicine Foundation Second Trimester Screening Group. Cervical length at mid-pregnancy and the risk of primary cesarean delivery. N Engl J Med 2008;358:1346-53.

19. Parry S, Simhan $H$, Elovitz $M$, lams J. Universal maternal cervical length screening during the second trimester: pros and cons of a strategy to identify women at risk of spontaneous preterm delivery. Am J Obstet Gynecol 2012;207:101-6.

20. Szychowski JM, Owen J, Hankins G, lams J, Sheffield J, Perez-Delboy $A$, et al. Timing of mid-trimester cervical length shortening in high-risk women. Ultrasound Obstet Gynecol 2009;33:70-5. 


\section{Obstetrics \& Gynecology Science}

Jee Yoon Park, et al. Cervical length in mid-trimester and vacuum-assisted delivery

21. Colombo DF, lams JD. Cervical length and preterm labor. Clin Obstet Gynecol 2000;43:735-45.

22. Owen J, Szychowski JM, Hankins G, lams JD, Sheffield JS, Perez-Delboy A, et al. Does midtrimester cervical length $\geq 25 \mathrm{~mm}$ predict preterm birth in high-risk women? Am J Obstet Gynecol 2010;203:393.e1-5.

23. Society for Maternal-Fetal Medicine, McIntosh J, Feltovich $\mathrm{H}$, Berghella $\mathrm{V}$, Manuck T. The role of routine cervical length screening in selected high- and low-risk women for preterm birth prevention. Am J Obstet Gynecol 2016;215:B2-7.

24. Khalifeh A, Berghella V. Universal cervical length screening in singleton gestations without a previous preterm birth: ten reasons why it should be implemented. Am J Obstet Gynecol 2016;214:603.e1-5.

25. Boelig RC, Orzechowski KM, Berghella V. Cervical length, risk factors, and delivery outcomes among women with spontaneous preterm birth. J Matern Fetal Neonatal Med 2016;29:2840-4.

26. Werner EF, Hamel MS, Orzechowski K, Berghella V, Thung SF. Cost-effectiveness of transvaginal ultrasound cervical length screening in singletons without a prior preterm birth: an update. Am J Obstet Gynecol 2015;213:554.e1-6.

27. Orzechowski KM, Boelig R, Nicholas SS, Baxter J, Berghella $V$. Is universal cervical length screening indicated in women with prior term birth? Am J Obstet Gynecol 2015;212:234.e1-5.

28. Berghella V. Universal cervical length screening for prediction and prevention of preterm birth. Obstet Gynecol Surv 2012;67:653-8.

29. Boelig RC, Suhag A, Guarente J, Orzechowski K, Berghella $\mathrm{V}$. Second-trimester cervical length and outcomes of induction of labor at term. J Matern Fetal Neonatal Med 2018;31:1040-4.

30. Boelig RC, Orzechowski KM, Suhag A, Berghella V. Second trimester cervical length and prolonged pregnancy. J Matern Fetal Neonatal Med 2016;29:4088-91.

31. Nicholas SS, Orzechowski KM, Berghella V, Baxter JK. Second trimester cervical length and its association with vaginal birth after cesarean delivery. Am J Perinatol 2016;33:20-3.

32. Ramanathan G, Yu C, Osei E, Nicolaides KH. Ultrasound examination at 37 weeks' gestation in the prediction of pregnancy outcome: the value of cervical assessment. Ultrasound Obstet Gynecol 2003;22:598-603. 